\title{
A $50 \%$ increase in the mass of terrestrial particles delivered by the Mackenzie River into the Beaufort Sea (Canadian Arctic Ocean) over the last 10 years
}

\author{
D. Doxaran ${ }^{1}$, E. Devred ${ }^{2}$, and M. Babin ${ }^{2}$ \\ ${ }^{1}$ Laboratoire d'Océanographie de Villefranche, UMR 7093 CNRS-UPMC, Villefranche-sur-Mer, France \\ ${ }^{2}$ Takuvik Joint International Laboratory, CNRS - Université Laval, Québec, Canada
}

Correspondence to: D. Doxaran (doxaran@obs-vlfr.fr)

Received: 12 November 2014 - Published in Biogeosciences Discuss.: 7 January 2015

Revised: 27 April 2015 - Accepted: 28 April 2015 - Published: 9 June 2015

\begin{abstract}
Global warming has a significant impact on the regional scale on the Arctic Ocean and surrounding coastal zones (i.e., Alaska, Canada, Greenland, Norway and Russia). The recent increase in air temperature has resulted in increased precipitation along the drainage basins of Arctic rivers. It has also directly impacted land and seawater temperatures with the consequence of melting permafrost and sea ice. An increase in freshwater discharge by main Arctic rivers has been clearly identified in time series of field observations. The freshwater discharge of the Mackenzie River has increased by $25 \%$ since 2003 . This may have increased the mobilization and transport of various dissolved and particulate substances, including organic carbon, as well as their export to the ocean. The release from land to the ocean of such organic material, which has been sequestered in a frozen state since the Last Glacial Maximum, may significantly impact the Arctic Ocean carbon cycle as well as marine ecosystems.

In this study we use 11 years of ocean color satellite data and field observations collected in 2009 to estimate the mass of terrestrial suspended solids and particulate organic carbon delivered by the Mackenzie River into the Beaufort Sea (Arctic Ocean). Our results show that during the summer period, the concentration of suspended solids at the river mouth, in the delta zone and in the river plume has increased by 46 , 71 and $33 \%$, respectively, since 2003 . Combined with the variations observed in the freshwater discharge, this corresponds to a more than $50 \%$ increase in the particulate (terrestrial suspended particles and organic carbon) export from the Mackenzie River into the Beaufort Sea.
\end{abstract}

\section{Introduction}

The Arctic Ocean plays an important role in the global carbon cycle as it contributes to up to $14 \%$ of the global ocean uptake of atmospheric carbon dioxide (Bates and Mathis, 2009). Observations over the last 20 years have revealed significant impacts of climate change at high latitudes, notably in the Arctic Ocean and surrounding coastal zones (Serreze et al., 2000; Macdonald et al., 2005). Air temperature has increased by $1^{\circ} \mathrm{C}$ since 1980 (Overland et al., 2011). Precipitation over the drainage basin of the Arctic Ocean, the largest after the Atlantic Ocean, has overall increased by $100 \mathrm{~mm} \mathrm{yr}^{-1}$ since 2000 but with strong regional differences (Rawlins et al., 2006). Consequently the freshwater discharge from major Arctic rivers has also increased (e.g., Fig. 1; Shiklomanov et al., 2007; Wisser et al., 2010; Shiklomanov and Lammers, 2011). Finally, permafrost has been found to gradually thaw (Smith et al., 2005; Zhang et al., 2012; Price et al., 2013). Permafrost is known to contain large amounts of frozen organic matter sequestered since the Last Glacial Maximum. The combination of permafrost thawing and increase in Arctic river freshwater discharge ( $\mathrm{Li}$ et al., 2009) may lead to an increase in the flux of terrestrial substances delivered by rivers into the Arctic Ocean.

More than 10 years ago, Syvitski (2002) used a stochastic model to estimate the impact of climate change (warming of Arctic regions) on sediment discharge by Arctic rivers. His study predicted a $22 \%$ increase in the flux of sediment exported by rivers for every $2{ }^{\circ} \mathrm{C}$ warming of the averaged drainage basin temperature and an increase of $10 \%$ in sediment load for a $20 \%$ increase in river discharge. Recent ad- 

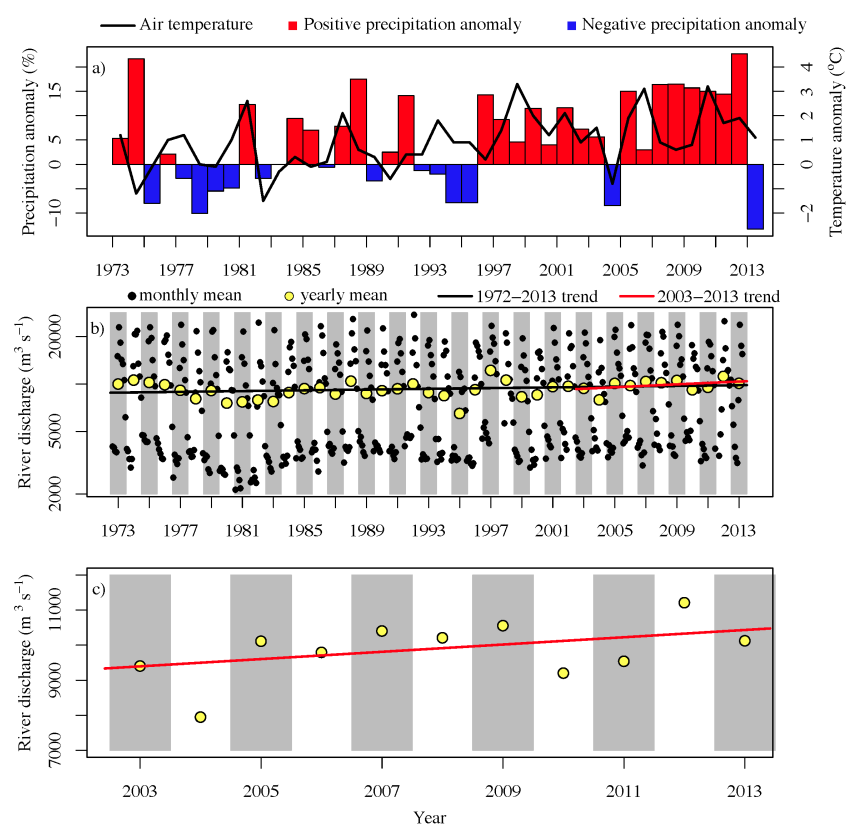

Figure 1. Variations in air temperature and precipitation anomalies observed in the Mackenzie drainage basin from 1973 to 2013 (a). Variations in the Mackenzie freshwater discharge (monthly and yearly averages); trends observed between 1973 and 2013, and between 2003 and 2013 (b). Zoom on the variations in the Mackenzie freshwater discharge between 2003 and 2013 (c).

vancements in measuring capabilities may now give us the possibility to confirm, or disprove, the realism of such predictions.

While field observations have been and are still scarce in such remote regions (e.g., along the drainage basins of North American and Siberian rivers), a methodology has been recently developed to remotely sense the variations in suspended particulate matter (SPM) concentrations at the mouth of Arctic rivers using ocean color radiometry (Doxaran et al., 2012). Since ocean color satellite data that cover more than a decade (see, for instance, Doxaran et al., 2009) are available, this method can be combined with field measurements of the river discharge and particulate organic content to estimate the actual mass of terrigenous particles (suspended particulate matter and particulate organic carbon (POC)) supplied to the ocean by any Arctic river and to study its seasonal and interannual variations.

The present study focuses on the mouth and turbid plume of the Mackenzie River in the Beaufort Sea (Canadian Arctic Ocean). This river is the largest single source of terrestrial particles entering the Arctic Ocean. The regional ocean color algorithm developed by Doxaran et al. (2012) for this area is based on a large bio-optical in situ data set collected in 2009 during the MALINA oceanographic campaign. It has been successfully tested on a selection of cloud-free and sea-icefree ocean color satellite images recorded during the 2009, 2010 and 2011 summer periods. It is here first improved

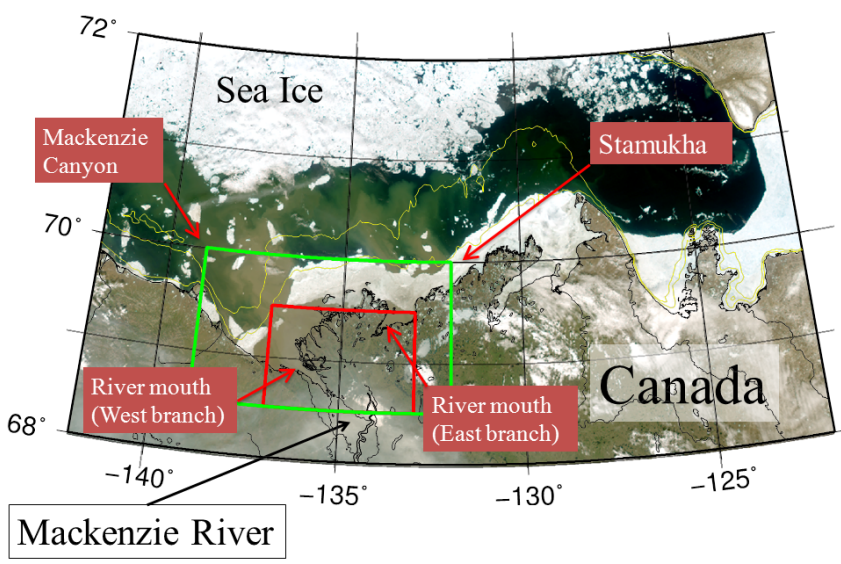

Figure 2. Quasi-true-color MODIS-Aqua image recorded on 24 June 2004 (250 m spatial resolution). The study area includes the (i) Mackenzie River mouth west and east branches (red box) and delta zone (green box) and (ii) the Beaufort Sea in the Canadian Arctic Ocean. During winter time the connection between the river delta and adjacent coastal waters is closed by the stamukha while drifting sea ice develops offshore.

to efficiently discriminate the floating sea ice, clouds, haze and highly turbid waters near the mouth of the Mackenzie River by tuning processing flags and visually inspecting every single pass. It is then applied to an 11-year-long data set of ocean color observations from the Moderate Resolution Imaging Spectroradiometer (MODIS) onboard the Aqua satellite platform. Results are used to estimate the monthly fluxes of SPM and terrestrial POC delivered by the Mackenzie River to the Beaufort Sea during the melting season in order to reveal possible trends resulting from the observed increase in freshwater discharge since 2003 (Fig. 1). The evolution of the floating sea-ice cover and extension of the Mackenzie River plume are also analyzed and discussed.

\section{Data and methods}

\subsection{Study area}

The southeast of the Beaufort Sea is characterized by the presence of a large and shallow continental shelf bordered to the east by the Amundsen Gulf, to the west by the Mackenzie canyon, to the south by the delta of the Mackenzie River, and to the north by the Beaufort Sea and Canada Basin (Fig. 2, Carmack and MacDonald, 2002). Two river mouths characterize the shallow delta zone: one in the west, where both the river flow and water turbidity are usually large, and one in the east, with a low river flow. During the winter period, sea ice accumulates north of the delta zone resulting in the formation, along the $20 \mathrm{~m}$ isobath, of a ridged ice barrier of considerable thickness $(>20 \mathrm{~m}$ ) grounded on the sea bottom, known as the stamukhi zone or stamukha (Macdonald et al., 1995). During that period, the water from the Mackenzie 
River is trapped in the delta zone and forms what is essentially a lake of turbid freshwater (Carmack and Macdonald, 2002). The spring ice breakup begins with the flooding of the Mackenzie River. When the river flow is maximal (June), the turbid freshwaters inundate the coastal zone and contribute to the progressive breaking of the stamukha (Fig. 2). The warm and turbid river plume can then spread over an area of several thousand square kilometers up to an offshore limit of permanent floating sea ice (Macdonald et al., 1995). The extension and dynamics of the plume are mainly controlled by wind conditions. During the summer period, melting sea ice and inputs from the Mackenzie River result in a 5 to $10 \mathrm{~m}$ surface layer of freshwater over the continental shelf. In September, the shelf is usually completely free of sea ice up to around $72^{\circ}$ N. Suspended particles supplied by the river are transported across the continental shelf either in a surface plume or a benthic nepheloid layer. This transport is controlled by circulation patterns on the shelf, which are driven by wind forcing, river discharge and sea-ice coverage (Ehn et al., 2015).

\subsection{Satellite data and SPM algorithm}

\subsubsection{Ocean color satellite data}

As in Doxaran et al. (2012), the selected ocean color satellite data are those recorded by the MODIS sensor onboard the Aqua platform. This sensor has provided at least one image of the study area every day since 2002 and has several bands in the near-infrared (NIR) and shortwave infrared (SWIR) spectral regions which are required for atmospheric corrections over turbid coastal waters (Wang and Shi, 2007). A single satellite sensor was used in this study in order to generate a consistent time series of SPM concentration.

MODIS-Aqua level-1 data were downloaded from the National Aeronautics and Space Administration (NASA) OceanColor website (http://oceancolor.gsfc.nasa.gov) and processed using the SeaWiFS Data Analysis System (SeaDAS 7.0.2) software (http://seadas.gsfc.nasa.gov/). The 11-year time series runs from 2003 to 2013 and includes the months of May to September, which correspond to the daylight period and ice-free season in most of the Arctic Ocean. No data were available between October and April due to ice cover and the polar night; however, these missing data do not impact our results significantly. In April, the river discharge is close to its annual minimum (reached in March, results not shown) and sediment transport is low. In October, the river discharge is low and the onset of the winter freeze-up reduces the export of sediment from the permafrost to the Mackenzie River.

Removal of the atmospheric contribution to the total signal was performed using the NIR-SWIR algorithm of Wang and Shi (2007); this correction method was proved to be the most appropriate for the highly turbid waters (high SPM load) present in the mouth the Mackenzie River (Doxaran et al.,
2012). Due to high loads of SPM in the Mackenzie Delta, a number of marine pixels were often classified as clouds or ice-covered in the standard SeaDAS processing (i.e., using the default mask threshold values) due to high reflectance values in the near-infrared spectrum. This issue was tackled by increasing the cloud albedo threshold for cloud flagging in the atmospheric correction procedure from the initial value of 0.027 to 0.4 in a small area bounded in the east from -133.4 to $-138.9^{\circ} \mathrm{E}$ and in the north from 68.7 to $69.3^{\circ} \mathrm{N}$ (Fig. 2). The relaxation of the cloud albedo criteria was combined with a careful visual inspection of every individual pass to avoid contamination by clouds in the delta, which occurred as speckles of very high SPM concentrations. Finally, observations over the delta, when available, were merged with the observation carried out with the standard atmospheric correction scheme to obtain maps of the whole study area (Fig. 3). The atmospheric correction procedure yielded remote-sensing reflectances $\left(R_{\mathrm{RS}}\right.$ in $\left.\mathrm{sr}^{-1}\right)$ at 555 and $748 \mathrm{~nm}$, which were used to derive the suspended particulate matter concentration (see next section). Satellite products were generated at a spatial resolution of $1 \mathrm{~km}$ at nadir.

From an initial total of about 10000 images taken over the study area and covering the period from 2003 to 2013, only 562 images were ultimately used in the present study despite the large number of MODIS-Aqua revisits at high latitudes. This emphasizes the need for a constellation of low-earthorbit ocean color satellites to increase the number of observations in such areas, which are highly affected by clouds and sea ice. Due to the very high sea-ice and cloud covers, the data recorded during the months of April and May ultimately proved to be unusable for SPM retrieval and were discarded from our analysis. Interestingly, the number of images per month increases with time over the observation period (2003-2013). This is consistent with the receding of seaice concentration over the last decade. The highest number of images in 1 month was reached in July 2012 (Fig. 4), a year of record-low sea-ice extent (Perovich et al., 2013). While the minimum of sea-ice extent occurs in September (usually a very cloudy month in this region), the highest number of satellite observations occurs in July, when daylight lasts for more than 20 hours, with higher sun zenith angles compared to the month of September allowing a greater number of observations per day in July than in September. The number of available images for each month was recorded to weight the linear regression of monthly SPM concentration against time during time series analysis.

\subsubsection{SPM algorithm and flux estimation}

The suspended particulate matter (SPM) concentration varies over 4 orders of magnitude (typically from 0.1 to more than $100 \mathrm{~g} \mathrm{~m}^{-3}$ ) from the highly turbid waters of the Mackenzie Delta to the oligotrophic region of the Beaufort Sea (e.g., Doxaran et al., 2012). At high SPM concentration, the seawa- 


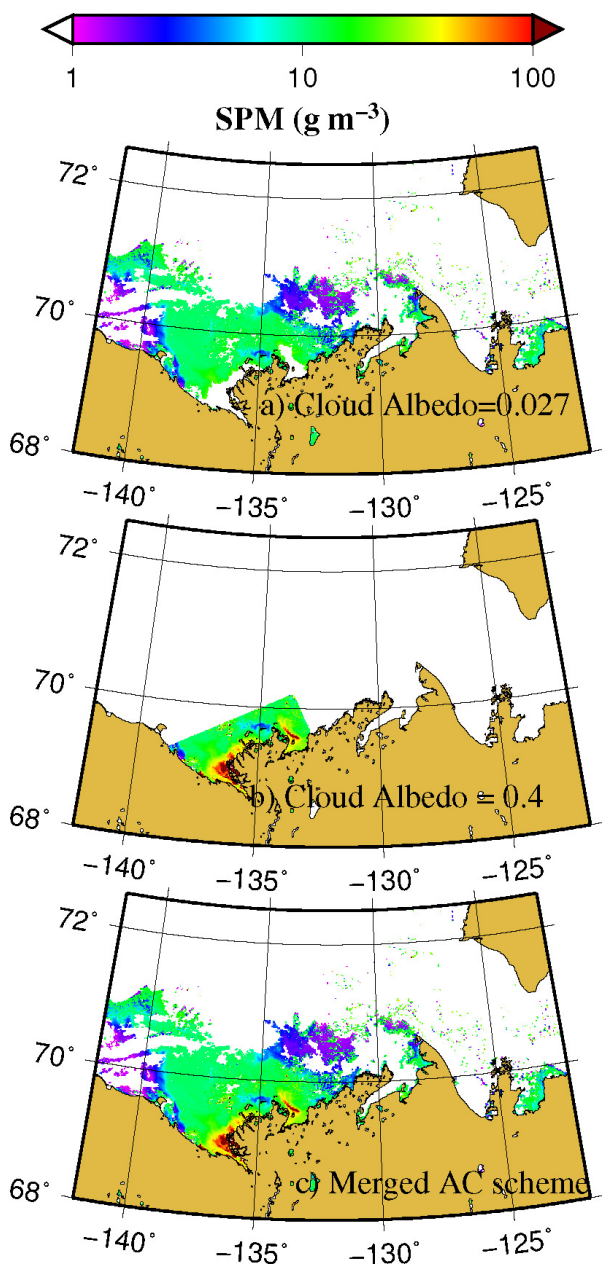

Figure 3. Example of processing (atmospheric corrections to retrieve the remote-sensing reflectances at 555 and $748 \mathrm{~nm}$, then inversion of the $748: 555$ reflectance band ratio into SPM concentration) applied to Level-1B MODIS-Aqua data from 4 July 2007: (a) NIR-SWIR atmospheric correction with default mask thresholds; (b) NIR-SWIR atmospheric correction with cloud-albedo threshold set to 0.4 (instead of 0.027 ) in the river delta zone; (c) merged product.

ter reflectance signal tends to be saturated in the visible part of the spectrum and only the signal in the near-infrared (NIR) spectrum remains sensitive to SPM variations (Doxaran et al., 2002; Shen et al., 2010). Therefore, as one of the main objectives of the study was to quantify SPM concentration and estimate SPM flux at the mouth of the Mackenzie River, a relationship had to be established between $R_{\mathrm{RS}}$ in the NIR and the SPM concentration. Doxaran et al. (2012) established such a regional relationship, using the $748 \mathrm{~nm}$ (MODIS band 15) to $555 \mathrm{~nm}$ (MODIS band 4) remote-sensing reflectance ratio in a second-order polynomial equation, based on field bio-optical measurements carried out in the study area during the MALINA oceanographic campaign (in-water and abovewater radiometric measurements were used to compute the

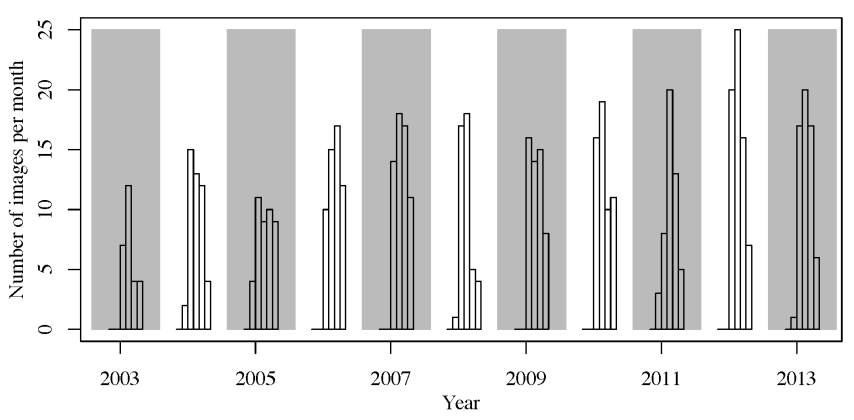

Figure 4. Number of Level-2 images available for each month of the time series (images selected after visual inspection).

$R_{\mathrm{RS}}$ signal; water samples were collected at $0.2 \mathrm{~m}$ depth using either a Niskin or a glass bottle for the determination of the SPM concentration (see Doxaran et al., 2012, for details)). This second-order polynomial relationship is valid for a wide range of SPM concentrations covering 1 to $150 \mathrm{~g} \mathrm{~m}^{-3}$, i.e., from the mouth of the Mackenzie River up to the offshore limit of the river plume. This second-order polynomial expression can accurately be described by two linear relationships: one developed for moderately turbid waters and a second one developed to deal with a high concentration of SPM. To avoid a sudden change in the SPM concentration as a function of the $R_{\mathrm{RS}}(748): R_{\mathrm{RS}}(555)$ spectral band ratio, a nonlinear equation (Eq. 1) was used to describe transition between both linear relationships:

$$
\begin{aligned}
& \mathrm{SPM}=0.8386 \times R_{\mathrm{RS}}(748: 555) \\
& \quad \text { if } R_{\mathrm{RS}}(748: 555)<87 \%, \\
& \mathrm{SPM}=70+0.1416 \times R_{\mathrm{RS}}(748: 555)+2.9541 \times \\
& \quad \exp \left[0.2092 \times\left(R_{\mathrm{RS}}(748: 555)-87\right)\right] \\
& \quad \text { if } 87 \% \leq R_{\mathrm{RS}}(748: 555) \leq 94 \%, \\
& \mathrm{SPM}=3.922 \times R_{\mathrm{RS}}(748: 555)-285.4 \\
& \quad \text { if } 94 \%<R_{\mathrm{RS}}(748: 555),
\end{aligned}
$$

where SPM is the SPM concentration in grams per cubic meter and $R_{\mathrm{RS}}(748: 555)$ is the ratio of remote-sensing reflectance at 748 to $555 \mathrm{~nm}$.

The use of two linear relationships is needed as the remotesensing reflectance signal in the NIR linearly increases with increasing SPM concentration up to about $90 \mathrm{~g} \mathrm{~m}^{-3}$ and then starts to become saturated at higher concentrations. Moreover, the sensitivity of the $R_{\mathrm{RS}}(748)$ signal is lower and therefore not optimal in the lowest SPM range, namely 1 to $10 \mathrm{~g} \mathrm{~m}^{-3}$, which corresponds to the offshore limit of the river plume. In this case, shorter wavelengths such as $555 \mathrm{~nm}$ (i.e., the green part of the spectrum) are better suited (Nechad et al., 2010). As a consequence, our regional algorithm is expected to accurately retrieve the SPM concentration in the delta zone and map the extension of the river plume but is potentially associated with higher uncertainties in the retrieval of SPM concentrations in the less turbid waters of the river 
plume (i.e., SPM lower than $10 \mathrm{~g} \mathrm{~m}^{-3}$ ). To circumvent this issue, the Mackenzie plume was here defined as the water mass with surface SPM concentrations higher than $10 \mathrm{~g} \mathrm{~m}^{-3}$, a rather conservative threshold.

The semiempirical relationship was established based on field measurements collected during the 2009 summer period. It is assumed here to be valid for the entire period of satellite observations (2003-2013). The uncertainty associated with the remotely sensed SPM concentrations derived from our algorithm is estimated as $\pm 25 \%$ based on (i) matchups with in situ data (when applying a similar SPM quantification algorithm to another study area: the Gironde Estuary, France; Doxaran et al., 2009) and (ii) in situ measurements in the Mackenzie Delta zone (see Fig. 6 in Doxaran et al., 2012).

The SPM flux was computed each month, from June to September, simply by multiplying the monthly-averaged SPM concentration (in grams per cubic meter) by the monthly-averaged freshwater discharged by the river (in cubic meters per second) and by the duration (in seconds) of the month. This approach is simplistic but gives a robust estimate of average SPM fluxes in the very shallow river mouth and delta zones. It does not require measurements of vertical profiles of current velocities. The estimates were computed for two specific geographical zones: (i) the river mouth defined as a box with the boundaries $68.7-69.5^{\circ} \mathrm{N}$ and $133-137^{\circ} \mathrm{W}$, where the offshore limit is roughly the $5 \mathrm{~m}$ isobath and (ii) the delta zone, also defined as a box with the boundaries 68.7$70^{\circ} \mathrm{N}$ and $132-139^{\circ} \mathrm{W}$, where the offshore limit is roughly the $20 \mathrm{~m}$ isobath.

\subsubsection{Sea-ice concentration}

Satellite-derived sea-ice concentration, expressed in percent $(\%)$, corresponds to the area of a pixel covered by sea ice relative to the total area of that pixel, such that a value of 100 indicates a pixel that is totally covered by sea ice and a value of 0 indicates a pixel free of sea ice. It is computed using a linear combination of the ratios of brightness temperatures measured in the microwave spectrum using the NASA Team 2 algorithm (Markus and Cavalieri, 2000).

Daily sea-ice concentration data were downloaded from the ftp server of the Zentrum für Marine und Atmosphärische Wissenschaften (ZMAW, ftp-projects.zmaw.de) for the period from 2003 to 2013. A series of three sensors with a spatial resolution of $6.25 \mathrm{~km}$ was used to cover the time period of MODIS-Aqua observations. For 2003 to 2011, data from the Advanced Microwave Scanning Radiometer - Earth Observing System (AMSR-E) were used until it stopped producing data. The new satellite AMSR2, launched in January 2013, was used to estimate the sea-ice concentrations in 2013. The gap between the AMSR-E and AMSR2 sensors (2012) was filled using data from the Special Sensor Microwave Imager/Sounder (SSMIS). Sea-ice concentration was used to flag potentially contaminated water pixels (isolated wa-
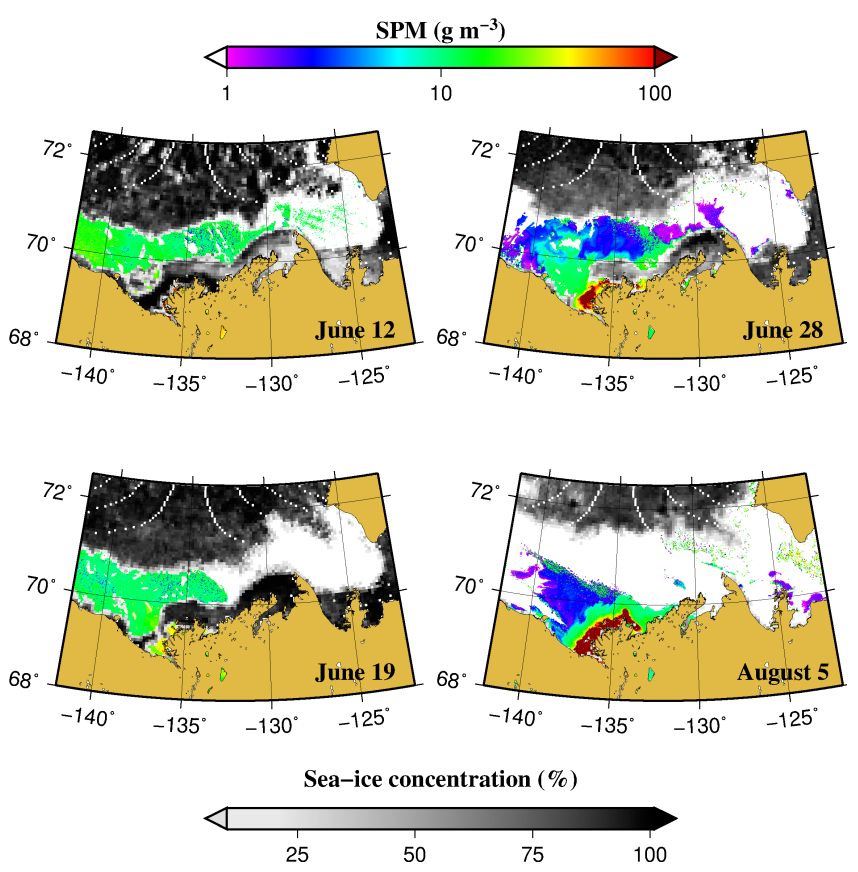

Figure 5. Typical SPM and sea-ice concentration (in grams per cubic meter and percent, respectively) maps obtained over the study area for selected days in June, July and August 2004. From June to July the breaking of the stamukha results in the discharge of turbid freshwater from the Mackenzie River into the Beaufort Sea. Even during the summer period the delta zone remains the most turbid area (maximal SPM concentrations).

ter pixels surrounded by highly reflective sea ice sometimes present erroneous high reflectance values due to adjacency effects). For this reason, ocean color data collected over pixels with a sea-ice concentration greater than $10 \%$ were removed from our analysis following Bélanger et al. (2007). The data were also used in a time series analysis to obtain information on the variations in sea-ice cover over time in the region of interest.

\subsubsection{Daily observations of SPM and sea-ice concentrations}

Figure 5 illustrates the resulting observations made regarding each individual MODIS satellite image when combined with the daily mapped sea-ice concentration data. This example shows the spectacular spring ice breakup event (typically occurring in early or mid-June) and highlights the rapid stamukha breakdown, which allows the turbid freshwaters of the Mackenzie River initially constrained in the delta zone to spread over the Beaufort Shelf. Figure 5 also highlights the contrast between the spring and the midsummer period (early August), by which time the coastal zone is totally free of ice. On 12 June 2004, a wide ice barrier extends all along the coast with sea-ice concentrations still close to $100 \%$ in the Mackenzie Delta zone, in the Amundsen Gulf and over most 
of the Beaufort Sea. Note that SPM concentrations in the icefree waters (between the stamukha and floating sea ice) are already high (about $10 \mathrm{~g} \mathrm{~m}^{-3}$ ) as turbid plumes can spread out in the continental shelf from below the stamukha (see, e.g., Fig. 2 for illustration). Not surprisingly, a week later (on 19 June), the breaking of the stamukha occurs first right in front of the Mackenzie River mouth (west side) where the river flow is at a maximum. The turbid plume clearly reaches as far as the offshore sea-ice edge, with SPM concentrations greater than $10 \mathrm{~g} \mathrm{~m}^{-3}$. Two weeks later, on 28 June, the seaice concentration along the coast has significantly decreased and the highest SPM concentrations (up to $100 \mathrm{~g} \mathrm{~m}^{-3}$ ) are located in the delta zone. The extension of the turbid plume has declined: the main direction of the plume closely follows the bathymetry towards the Mackenzie canyon while clear waters appear around the plume. Finally, 1.5 months later (5 August), during the midsummer period, the sea ice has almost disappeared along the coast and notably at the entrance of the Amundsen Gulf. Offshore the sea ice remains present but has retreated northwards following its seasonal cycle. The river plume reaches its maximum surface area with highly turbid waters at the river mouth and in the delta zone, contrasting with clear waters offshore.

These four daily snapshots provide an initial overview of the SPM and sea-ice seasonal dynamics over the study area. However, performing a multiyear and seasonal analysis of these two parameters requires the use of monthly-averaged composites.

\subsubsection{Monthly compositing and time series analysis}

Two main areas of interest are distinguished in the present study: (i) the river delta, as defined in Fig. 2, and (ii) the river plume defined as the area where SPM was greater than $10 \mathrm{~g} \mathrm{~m}^{-3}$. Whereas the delta surface area remains constant in time, the surface area of the plume changes as a function of the SPM concentration dynamics over the shelf of the Beaufort Sea in turn driven by the river discharge, wind and sea-ice cover conditions. Monthly gridded images were computed on a pixel-per-pixel basis using the arithmetic mean of all the measurements available in a given month. The monthly mean SPM concentrations for the Mackenzie Delta and plume (i.e., one value per month) were computed also by arithmetic mean within the area of interest, and the number of pixels used to compute each mean was recorded ( $\left.N_{\text {month }}\right)$.

The limited number of months with conditions suitable for ocean color observations due to ice cover and the polar night (i.e., about 4 months a year) prevents the use of common time series decomposition tools since it is not possible to obtain an entire annual cycle. We therefore preferred to use linear regressions of each satellite product (SPM, sea-ice concentration) against time to infer its trend. When performing the linear regression of monthly SPM concentration against time, the number of pixels available for each month, i.e. $N_{\text {month }}$, was used to weight the contribution of each month in the time series and give more importance to months with more data. The time series analysis was carried out for 2003 to 2013 (11 years) from the month of June to the month of September.

\section{Results}

\subsection{Seasonal dynamics of sea ice and suspended particulate matter}

We first look at the "seasonal" dynamics of SPM and sea ice in the region of interest. Here, the term "seasonal" refers to the monthly variations over the 4-month period (June to September) which corresponds to the maximal Mackenzie River discharge (Fig. 1). Also before analyzing the multiyear variations and potential trends, we highlight how different successive years can be in terms of sea-ice coverage and SPM dynamics.

Similar situations were observed in 2003 and 2004: in June, the ice extends all along the coast except in front of the west branch of the Mackenzie River mouth (Fig. 6). The water is highly turbid in the delta zone and also on the continental shelf, bounded in the north by the offshore sea-ice edge $\left(\sim 70.2^{\circ} \mathrm{N}\right)$ and in the east by the entrance of the Amundsen Gulf. One month later, in July, the coast is free of ice while the floating sea ice still covers the same area in the Beaufort Sea; a maximum turbidity zone has developed in the delta zone with SPM concentrations up to $100 \mathrm{~g} \mathrm{~m}^{-3}$, and the turbid plume still extends from the river mouth up to the offshore limit of sea ice. Progressively, in August and then in September, the extent and concentration of floating sea ice both decrease as does the concentration of SPM decreases on the continental shelf while it remains high in the delta zone.

The situation is much more unusual in June 2006 as the whole Beaufort Sea is covered by sea ice except along the coastline and in the Mackenzie Delta. These unusual June conditions return to the average conditions in July as the floating sea ice has moved northwards: extremely turbid waters then concentrate in the delta zone, while turbid plumes extend along the continental shelf. Once again in August and September, SPM concentrations progressively decrease on the shelf while remaining high in the delta zone. Opposite conditions are observed at the beginning of the 2008 summer period, with a minimum floating sea-ice cover observed from June to September (Fig. 7). SPM concentrations gradually decrease along the shelf during this period while remaining very high in the delta zone.

A high number of cloud-free days in 2011, 2012 and 2013 (Fig. 4) yield a maximum of satellite observations (Fig. 8). In 2011, the stamukha zone can still be observed in June as it progressively breaks, resulting in the presence of floating sea ice along the coast. High SPM concentrations extend from the delta zone to the continental shelf with the main river plume extending towards the Mackenzie Canyon. In August 

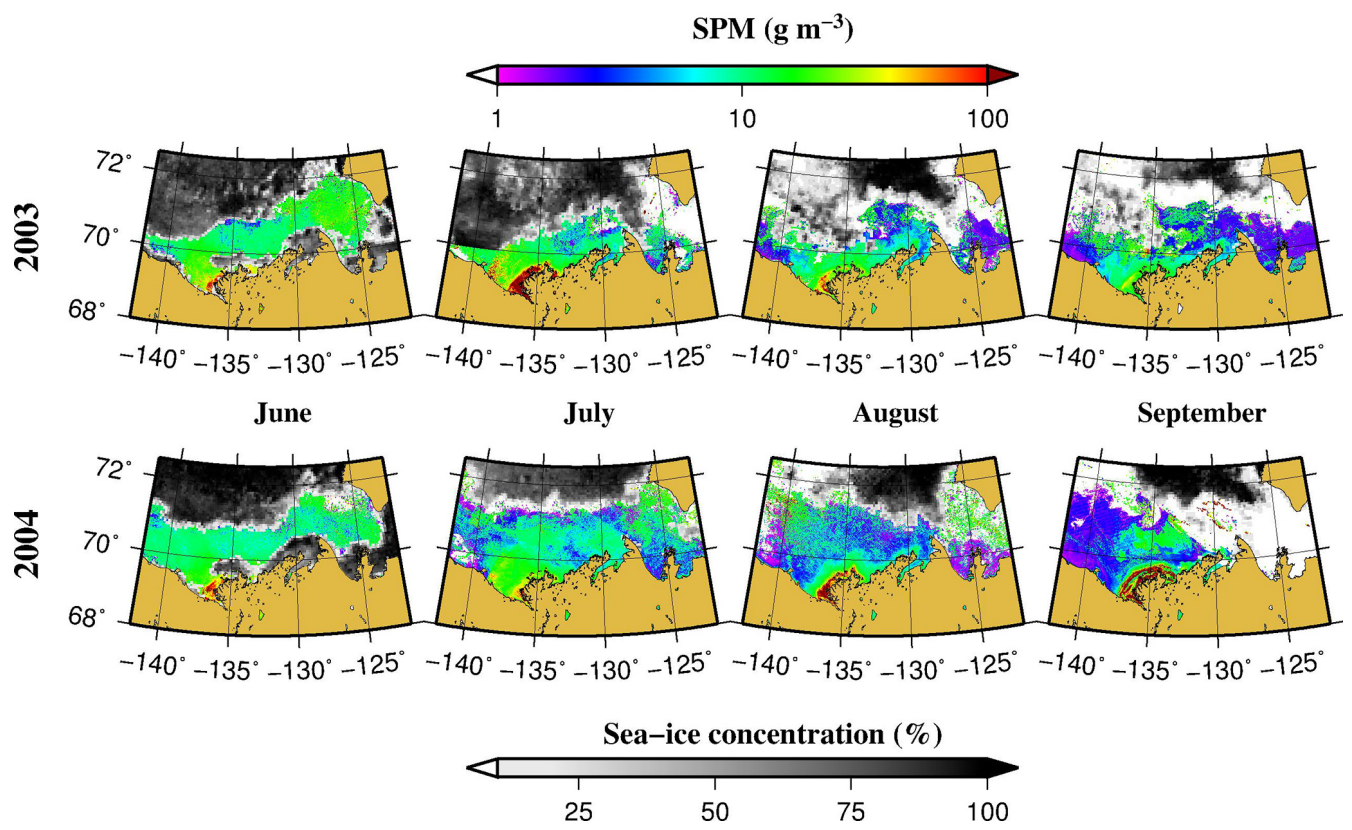

Figure 6. Monthly (June to September) composites of sea-ice and surface water SPM concentrations in 2003 and 2004.

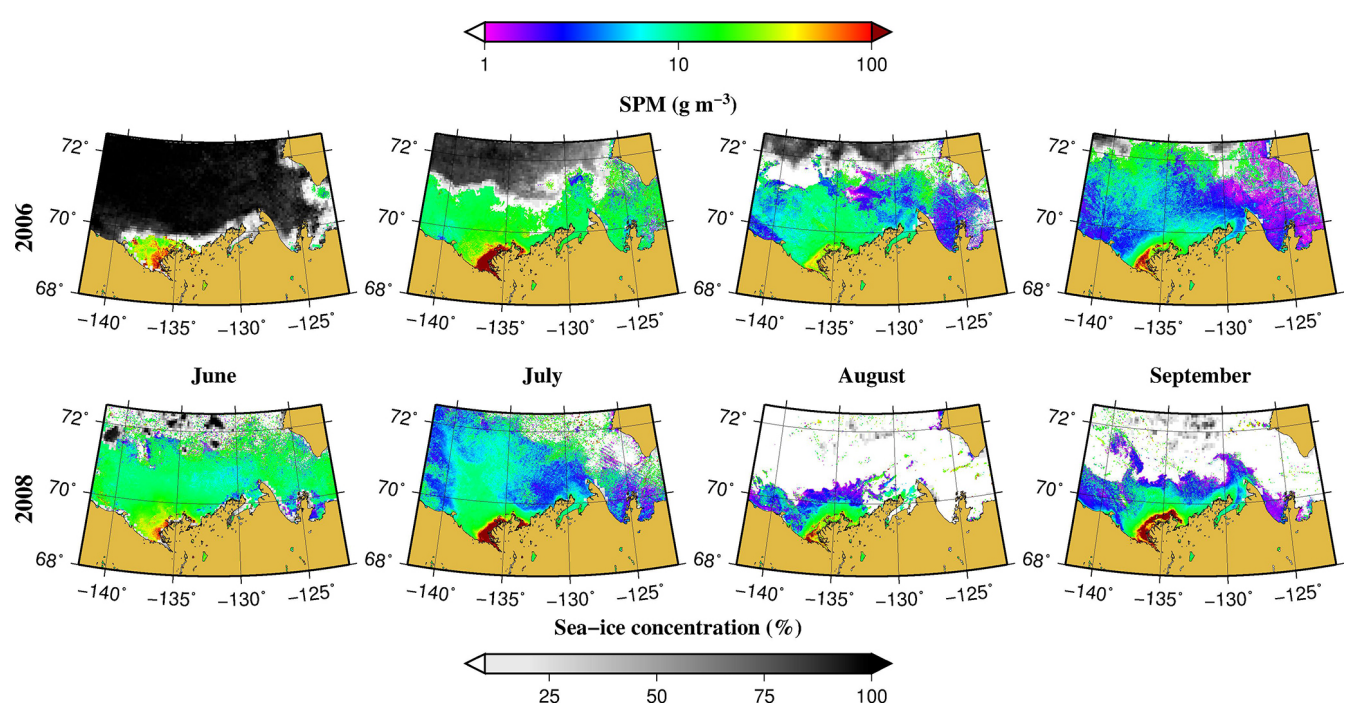

Figure 7. Same as Fig. 6 but for 2006 and 2008.

and September, high SPM concentrations are only detected in the delta zone, while clear waters cover most of the continental shelf. The minimum sea-ice cover is observed during the 2012 summer period, allowing turbid plumes with high SPM concentrations to extend up to $72.5^{\circ} \mathrm{N}$. Despite these favorable sea ice and cloud cover conditions, the monthly variations in SPM from June to September remain similar to the monthly variations during the previous years. Finally, opposite conditions to 2011 and 2012 are encountered in 2013, with sea ice covering most of the Beaufort Sea in June, as in 2006, with only the delta zone being free of ice. As the floating sea ice slowly migrates north from July to Septem- ber, the discharge of the Mackenzie freshwaters occurs later such that turbid waters extend over the continental shelf until August. The situation in September is finally similar to the previous years, with high SPM concentrations constrained to the delta zone and clear waters offshore.

\subsection{Multiyear dynamics of sea ice and SPM}

The month of June is probably the most interesting to consider regarding the extent of sea ice in the Beaufort Sea. The sea-ice cover depends primarily on the atmospheric conditions (air temperature and wind) during the long winter pe- 

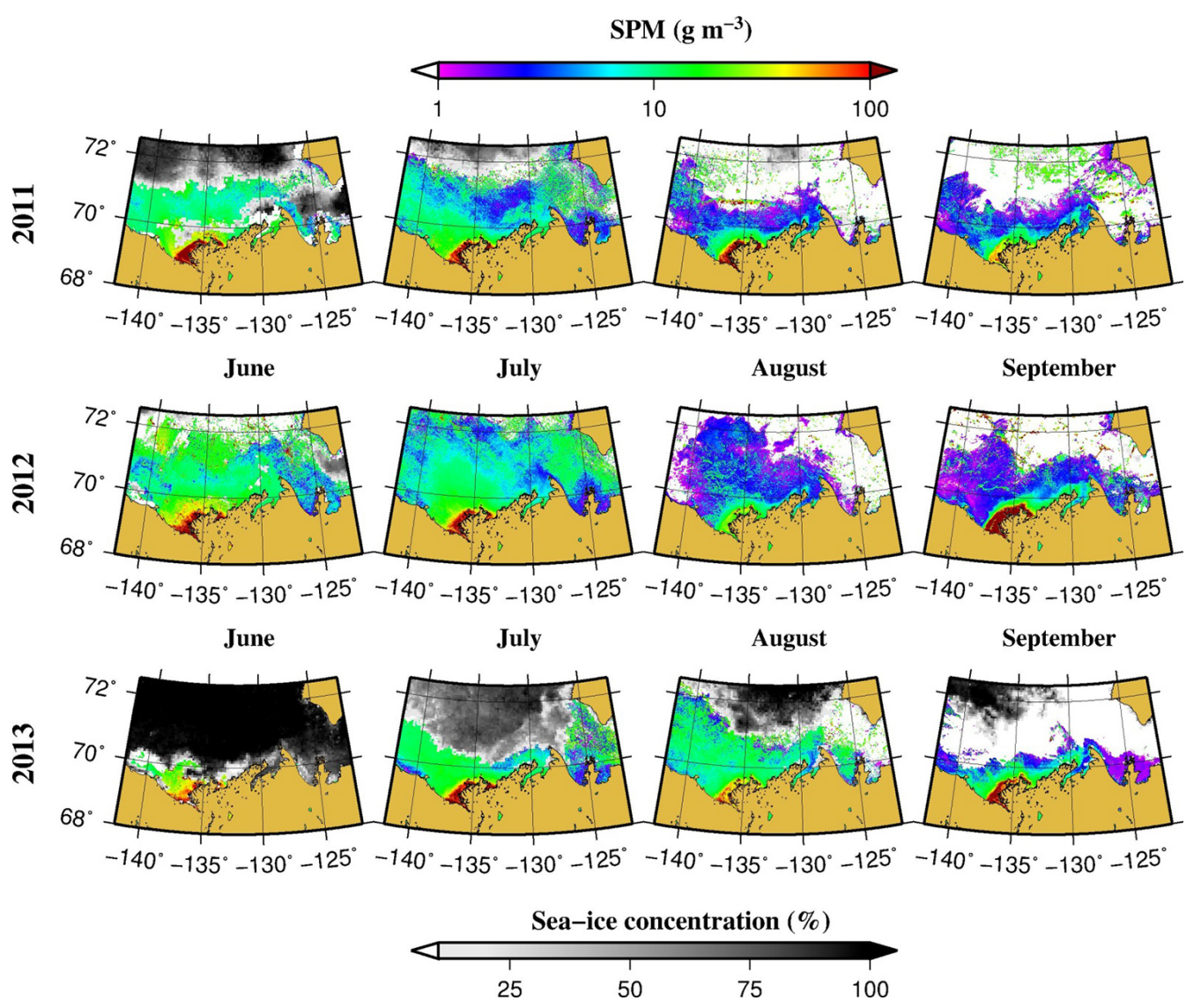

Figure 8. Same as Fig. 6 but for 2011, 2012 and 2013.

riod, when ice has formed and extended south from the very high latitudes (greater than $80^{\circ} \mathrm{N}$ ). Close to the shore, the sea-ice cover also depends on the air temperature and wind conditions along the coast, which determine the sea-ice concentrations and thickness of the stamukha. Sea ice is also affected by the heat content of the underlying ocean, which varies from year to year, including due to changes in largescale circulation. Finally, the June sea-ice extent is influenced by the freshwater discharge of the Mackenzie River during the spring period (April, May and June), which defines the upstream pressure imposed by the river on the ice barrier formed around the delta zone and which controls its breaking.

In June 2003, 2004 and 2005, similar conditions of sea ice and stamukha extent were observed, with (i) floating sea ice spreading over most of the southern Beaufort Sea up to $70.5^{\circ} \mathrm{N}$ and (ii) ice formed all along the coast up to the Amundsen Gulf. High SPM concentrations were then located in the delta zone, while turbid plumes extended up to the offshore limit of the sea ice. The following summer periods (July to September 2003 to 2005) also showed similar patterns, with a gradual regression of sea ice moving northwards and a decline in the SPM load and offshore extension of the turbid plumes, which were progressively constrained to the coast (delta zone). The years following 2005, i.e. 2006 to 2013, showed more pronounced monthly variations with very different situations encountered in June, such as an almost full coverage of the Beaufort Sea with sea ice in 2006 and 2013, and quasi ice-free conditions over the whole Beaufort Sea (up to $72.5^{\circ} \mathrm{N}$ ) in 2012. Between these two extreme situations (i.e. from full to null sea-ice coverage conditions in June), transition years (e.g., 2007, 2008 and 2009) showed intermediate sea-ice conditions, but on average the sea-ice extent over the Beaufort Sea in June significantly decreased from the 2003-2005 period to the most recent years. SPM dynamics over the summer period showed rather similar successive patterns during the last 11 years: first, there is the discharge of the highly turbid waters of the Mackenzie River previously trapped in the stamukha, then the offshore transport of SPM mainly towards the Mackenzie canyon and finally, at the end of the summer period, the trapping of SPM in the delta zone in contrast to clear waters (low SPM loads) over the Mackenzie Shelf.

It should be also noted that the number of MODIS-Aqua satellite observations over the study area, and thus the number of cloud-free and sea-ice-free days, significantly increased from 2003 to 2013. Therefore, before examining in detail the variations in SPM concentrations over this 11-year 
period, our analyses already reveal significant changes in both the sea ice and cloud cover in the Beaufort Sea region.

\subsection{Multiyear SPM concentrations and fluxes at the Mackenzie River mouth}

Data on the freshwater discharge of the Mackenzie River (for the station 10LC014 $\left(67^{\circ} 27^{\prime} 21^{\prime \prime} \mathrm{N}\right.$ and $133^{\circ} 45^{\prime} 11^{\prime \prime} \mathrm{W}$ ) from 1972 to 2013 were downloaded from the Environment Canada website (www.wateroffice.ec.gc.ca). They show large seasonal variations (Fig. 1), with a maximum during the summer period (from June to September) and lower values during the rest of the year (Macdonald et al., 1998; O'Brien et al., 2006). Over the last 11 years, this discharge typically varied between $4000 \mathrm{~m}^{3} \mathrm{~s}^{-1}$ (winter) and $25000 \mathrm{~m}^{3} \mathrm{~s}^{-1}$ (summer). Despite large year-to-year variations, a trend is found over this period, with a significant increase of $22 \%$ from 2003 to 2013.

The analysis of the monthly SPM maps generated for 2003 to 2011 provides a qualitative overview of the spatial and temporal variations in SPM concentrations in the Mackenzie mouth and delta, as well as in the Beaufort Sea. In order to quantify these variations and highlight a potential trend, these monthly-averaged SPM concentrations were plotted as a function of time, first only considering the Mackenzie Delta zone (see Fig. 2 for detailed geographical location).

For the 11 years of the time series, the 4-monthly-averaged SPM concentrations (June to September) revealed the SPM variations during the summer period (i.e., when the Mackenzie River mouth is directly connected to the Beaufort Sea), which gives a first overview of the load of SPM exported from the river to the coastal ocean (Fig. 9). These SPM concentrations vary from about 70 to $100 \mathrm{~g} \mathrm{~m}^{-3}$ during the 11year period, which is in agreement with field measurements collected along river transects (Doxaran et al., 2012). On average over a selected summer period, relative variations of $\pm 25 \%$ are observed, except in 2003 , when relative variations of $\pm 65 \%$ occurred. Note that the results obtained in 2003 may be associated with larger uncertainties due to the relatively low number of cloud-free satellite images available. The highest SPM concentration during the summer period in the Mackenzie Delta is usually, but not systematically, observed in June or July (e.g., in 2013, when a high number of cloud-free MODIS images were available). Despite these month-to-month variations, a striking result lies in the multiyear trend observed during our 11-year observation, which overall corresponds to an increase in the mean SPM concentration in the delta zone from 2003 to 2013. Over this 11-year period, the mean concentration increased from 71 to $107 \mathrm{~g} \mathrm{~m}^{-3}$, which represents a significant increase of $51 \%$ since 2003 . This linear increasing trend is obvious $\left(R^{2}=0.61\right)$ when considering the mean SPM concentration averaged each year over the 4-month observation time window (June to September). Such an increase of more than $50 \%$, observed over the 11-year period, is much higher than
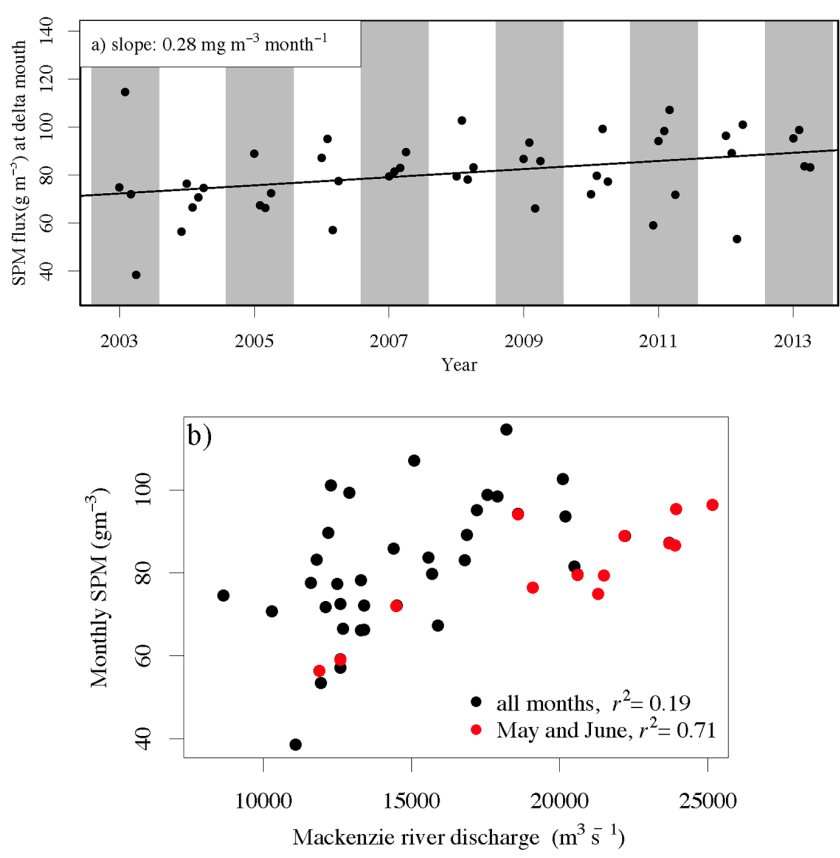

Figure 9. Multiyear (2003-2013) variations in and trend of the monthly-averaged SPM concentration at the Mackenzie River mouth (a). Plot of the monthly-averaged SPM concentration as a function of the monthly-averaged freshwater discharge: considering all months (white circles), and then only considering the months of May and June (red circles) (b). The determination coefficients $\left(R^{2}\right)$ corresponds to the best linear fits.

the uncertainty in the SPM concentration estimated from MODIS satellite data using our algorithm $( \pm 25 \%$, according to Doxaran et al., 2009, 2012); this is an uncertainty which is significantly minimized when producing monthly averages of SPM concentrations (assuming there is no correlation between SPM and clouds). Moreover, due to regular vicarious calibrations of the MODIS-Aqua sensor (Franz et al., 2007; Meister et al., 2012), a temporal degradation in the satellite data quality cannot alone explain the observed variations. This confirms the consistency of the result presented here. It is also important to bear in mind that a unique satellite sensor was used in this study and the exact same algorithm (atmospheric corrections of satellite data and inversion of the seawater signal into SPM concentration) was applied, precisely in order to avoid any bias or discrepancy related to sensor calibration and minimize the uncertainty of the satellite-derived SPM concentration. This gives us confidence in the validity of the increasing trend in monthly SPM concentration observed over the Mackenzie River delta and Beaufort Sea.

To further confirm this assumption, we examine the relationship between the monthly-averaged (i) Mackenzie freshwater discharge (in $\mathrm{m}^{3} \mathrm{~s}^{-1}$ ) and (ii) SPM concentration in the delta zone. A correlation can be expected between the two variables, since both increased by 22 and $51 \%$, respectively, 
from 2003 to 2013. However, SPM concentration correlated with freshwater discharge $\left(R^{2}=0.71, p\right.$ value $\left.<0.05\right)$ when considering only the months of May (1 point) and June (11 points), whereas no correlation $\left(R^{2}=0.07\right)$ was established when all the months (May to September) were taken into account (Fig. 9b). This suggests that the export of SPM from the Mackenzie River to the Beaufort Sea is largely driven by the Mackenzie River runoff during a short period of 2 months (May and June, i.e., late spring and early summer) corresponding to the maximum freshwater flow. Other mechanisms and processes may be involved during the other summer months, such as permafrost thawing and intense precipitation events that locally inject pulses of SPM in the Mackenzie River and Delta which are later exported to the Beaufort Shelf. In spring (May and June), the SPM passes through the delta zone to enter the coastal ocean (the spring freshet is often the period of most flux in many rivers as the velocities are sufficient to keep particles in suspension). As soon as the river freshwater discharge decreases (July to September), the SPM is trapped in the delta zone, where particle settling and resuspension due to tidal currents and wind stress will control the variations in SPM concentrations and export towards the continental shelf.

Having observed and quantified the increase of the Mackenzie freshwater discharge and SPM concentration at the river mouth, the next logical step is to look at the resulting variation in the SPM flux delivered by the river to the Arctic Ocean. The result is an estimation of the mass of SPM in grams $(\mathrm{g})$ transported downstream through the river mouth. The SPM flux obtained corresponds to the solid discharge of the Mackenzie River into the Beaufort Sea, i.e., the mass of SPM delivered by the river each month during the June to September summer period. The same SPM flux calculation is made in the delta zone but cannot be considered as horizontal downstream transport as this zone is also affected by SPM vertical dynamics (particle settling and resuspension of bottom sediments). Note that here we call the downstream limit of the Mackenzie River the river mouth, i.e., the geographical zone defined as the box with the boundaries 68.7$69.5^{\circ} \mathrm{N}$ and $133-137^{\circ} \mathrm{W}$. The delta zone is the geographical zone defined as the box with the boundaries $68.7-70^{\circ} \mathrm{N}$ and $132-139^{\circ} \mathrm{W}$.

The results obtained in the river mouth emphasize the large monthly variations in the SPM flux (by a factor of 6) during the summer period (Fig. 10a). The SPM flux is typically higher in June and July than in August and September, which can be explained by the variations in the Mackenzie River freshwater discharge. A strong interannual variability in the SPM flux is also observed, which is directly related to the interannual variability in the freshwater discharge. The timing of the breakup of the stamukha probably plays an important role in the interannual variability of the SPM flux by slowing down the river flow into the delta zone. As for the SPM concentrations (Fig. 9), a trend of increasing SPM flux is observed from 2003 to 2013. Fitting the time series
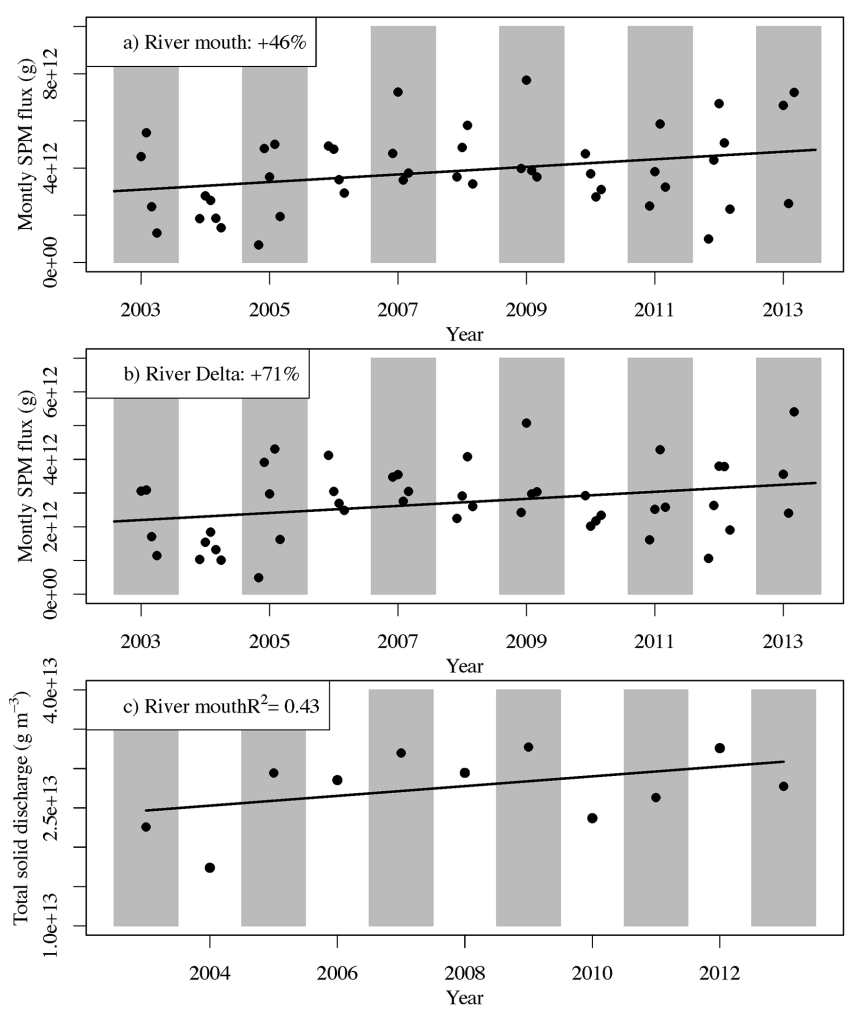

Figure 10. Monthly-averaged SPM flux (in g) estimated at the river mouth (geographical zone defined as a box with the boundaries $68.7-69.5^{\circ} \mathrm{N}$ and $133-137^{\circ} \mathrm{W}$ ) in June, July, August and September from 2003 to 2013 (a). Same but for the delta zone (geographical zone defined as a box with the boundaries $68.7-70^{\circ} \mathrm{N}$ and $132-$ $139^{\circ} \mathrm{W}$ ) (b). Total estimated mass (in $\mathrm{g}$ ) of SPM delivered by the Mackenzie River into the Beaufort Sea during the summer period (June to September) from 2003 to 2013 (c). Solid black lines correspond to the linear trend.

using a linear regression reveals a significant positive trend ( $p$ value $<0.05$ ) with a relative slope indicating a $46 \%$ increase over the 11-year-long period of observation. This result corresponds to about twice the increase observed in the river freshwater discharge (Fig. 1). Such an increase in the SPM flux may reflect enhanced erosion processes occurring along the drainage basin as a result of the warming air temperature and perhaps an acceleration of the thawing of the permafrost.

Similar observations are made in the delta zone (Fig. 10b). It is interesting to note that the SPM fluxes in the delta zone and at the river mouth are linearly correlated $\left(R^{2}=0.81\right)$, with SPM concentrations and SPM fluxes in the delta zone being approximately $30 \%$ lower than in the river mouth. This clearly indicates that rapid and intensive settling of particles occurs in the delta zone (e.g., Rontani et al., 2014). A second interesting observation is that the increase in SPM concentrations and therefore in the resulting SPM flux from 2003 to 2013 is higher in the delta zone $(+71 \%)$ than in the river 

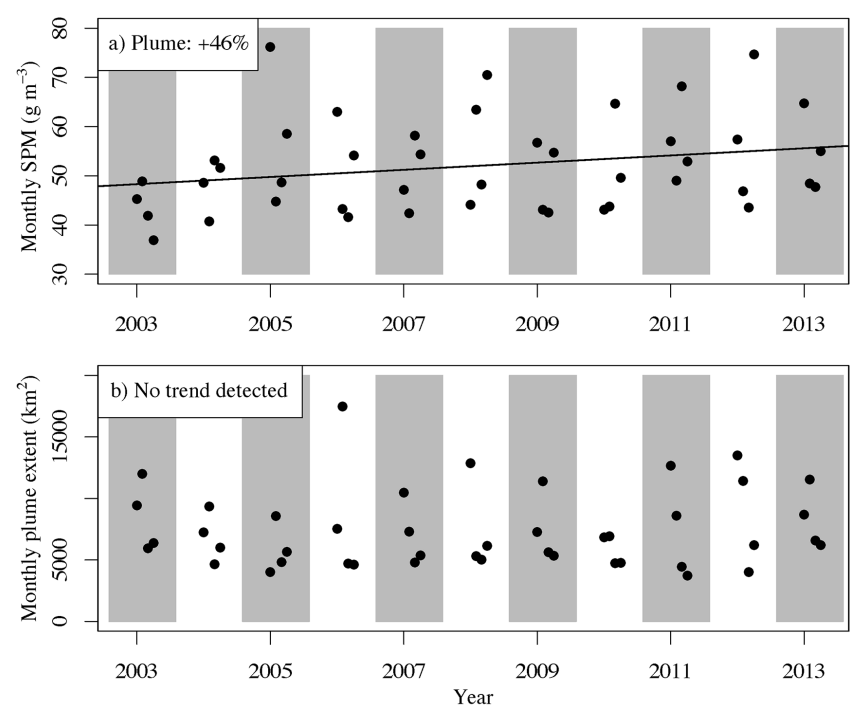

Figure 11. Multiyear (2003-2013) trends in the variation in the monthly-averaged SPM concentration in the Mackenzie River plume (a) and extent of the river plume (b).

mouth $(+46 \%)$. This certainly reflects an increase in water turbidity, i.e., in SPM load, in the delta zone, where particles rapidly settle to form a bottom nepheloid layer and/or deposit. Resuspension processes due to tidal currents and wind stress probably contribute in a non-negligible manner to the high SPM concentrations observed in this very shallow ( 2 to $5 \mathrm{~m}$ depths) zone; however, our method does not allow the separation of the different processes involved in the characterization of the SPM fluxes. Fitting a linear regression to the annual SPM fluxes as a function of time reveals a significant correlation of 0.43 at the river mouth (Fig. 10c). Note, however, 2 unusual years (2004 and 2010) associated with lower than expected SPM fluxes. This relationship may be useful for modeling and predicting, in the near future, the mass of SPM and associated organic carbon delivered by the Mackenzie River into the Beaufort Sea. Using this interannual linear trend, a significantly lower increase in SPM flux is obtained from 2003 to $2013:+36 \%$ against the $+46 \%$ that were obtained when considering the monthly-averaged SPM fluxes (Fig. 10a). This clearly means that the method used to estimate the changes in SPM concentrations and fluxes impacts the result. While we can confidently draw conclusions on the positive trends observed in the SPM concentration and fluxes, the magnitude of the variations reported here should be used carefully in other studies.

\subsection{Impact on the Mackenzie continental shelf}

We finally analyze the impact of the increase in SPM concentrations and fluxes in the river mouth and delta zone on the Mackenzie continental shelf (Fig. 11). Only the SPM concentrations (estimated using satellite data within the first few meters below the air-water interface; Doxaran et al., 2012) are considered here. Given the data available in this study, it is impossible to compute the SPM flux as we do not have access to the surface current velocity and direction. The extent of the plume over the study area is defined as the area where SPM concentrations are higher than $10 \mathrm{~g} \mathrm{~m}^{-3}$. This arbitrary threshold value was chosen because of the higher accuracy of our remote-sensing algorithm in the 10 to $100 \mathrm{~g} \mathrm{~m}^{-3} \mathrm{SPM}$ concentration range. The resulting mean SPM concentration in the river plume is logically lower than in the delta zone. It typically varies from 40 to $80 \mathrm{~g} \mathrm{~m}^{-3}$ (with a few values as low as $20 \mathrm{~g} \mathrm{~m}^{-3}$ ) (Fig. 11a), compared to variations from 60 to $120 \mathrm{~g} \mathrm{~m}^{-3}$ in the delta zone (Fig. 8). This simply highlights the balance between horizontal transport of SPM within surface waters, settling within the water column and degradation processes (see details in Rontani et al., 2014). Monthly variations in SPM concentrations in the river plume are slightly smoother than in the river mouth and delta zone, probably due to the large surface covered by the plume. A very similar trend of increasing concentrations is observed over the 11 -year period $(+33 \%)$. The turbidity of the water along the Mackenzie continental shelf is also rising, and this will certainly have a direct impact on the marine ecosystems since it will modify the nutrient balance (possible increase in primary production) but will also reduce the light availability within the water column (decrease in primary production) (see Forest et al., 2013, for detailed analyses). Increasing volumes of turbid freshwater delivered into the Mackenzie continental shelf will also impact the stratification of water masses (e.g., buoyancy of surface waters) and alter primary production.

The extent of the Mackenzie River plume mainly experienced strong month-to-month variations, being typically at a maximum in June and then progressively decreasing until August and September. This clearly reflects the observations made on the SPM maps (Figs. 6 to 8): the river plume spreads out over the shelf during the breakup of the stamukha and regresses to the coast, mainly in the delta zone, during the summer period as the river discharge and thus freshwater transport decrease. There is no significant interannual trend observed concerning the plume extent as it is mainly dependent on the sea-ice coverage and the regional hydrodynamics (Ehn et al., 2015). While SPM concentrations increase within the surface waters of the plume, its extension into the Beaufort Sea remains unchanged due to the presence of a pack of floating sea ice. A direct impact of the decrease in sea-ice extent on the primary productivity of Arctic waters has been observed (Arrigo et al., 2008; Tremblay et al., 2011). However, it is not understood yet whether this increase in terrestrial substances along the continental shelf contributes to the development of phytoplankton blooms under the Arctic sea ice (Arrigo et al., 2012). 


\section{Discussion}

An important result presented in the previous section concerns the significant increase of SPM flux at the mouth of the Mackenzie River observed over the last 11 years, with a potential effect not only on the marine ecosystem but also on the northern community. The erosion of the shoreline has dramatic consequences for the local community and an increase in sediment transport and deposition along the Beaufort Shelf could mitigate the impact of the erosion. However, a numerical model of ocean circulation would be required to properly assess the fate of the extra sediment exported. Another important aspect of our findings deals with the mass of terrestrial SPM (and subsequent POC) exported from the Mackenzie River to the Beaufort Sea and the balance of this budget with the sedimentation rates in the delta zone and continental shelf. Taking into account the degradation processes of the organic material within the water column (Bélanger et al., 2006) and the fate of bottom sediments (Chaillou et al., 2007), it is necessary to quantify the percentage of terrestrial organic matter that will be buried in marine sediments and attempt to explain it by taking into account the highly refractory state of POC transported by rivers (Hedges et al., 1997; Keil et al., 1997).

At the mouth of the Mackenzie River, water masses are transported downstream to enter the delta zone to supply it with dissolved and particulate materials. As a first approximation, the SPM flux estimated in the present study corresponds to the mass of SPM delivered by the river to the delta during the 4-month summer period (June to September). On average, from 2003 to 2013, the total mass of SPM estimated during this period is about $20( \pm 5) \times 10^{12} \mathrm{~g} \mathrm{y}^{-1}$, which is in good agreement with previous estimates made using a selection of cloud-free satellite images recorded in 2009, 2010 and 2011 (Doxaran et al., 2012). Assuming a constant POC: SPM organic content of $1.8 \%$ (mean value reported by Yunker et al., 1993, Emmerton et al., 2008, and Doxaran et al., 2012, while values as low as $1.1 \%$ and as high as $3.4 \%$ have been observed in the river mouth area during the June-September period), this leads to a total of $0.4( \pm 0.1) \times 10^{12} \mathrm{~g} \mathrm{Ca}^{-1}$ of terrestrial POC entering the delta zone through the Mackenzie River mouth. These values must be compared to previous estimates computed using field measurements (freshwater discharge and sediment loads) collected in the Mackenzie River hundreds of kilometers upstream of the delta zone (Macdonald et al., 1998): 120 $( \pm 5) \times 10^{12} \mathrm{~g} \mathrm{a}^{-1}$ for SPM and $2.0( \pm 0.5) \times 10^{12} \mathrm{~g} \mathrm{C} \mathrm{a}^{-1}$ for POC. There are a several reasons for such differences (which are of factor of 5 to 6) between SPM and POC values estimated in our study and those reported in Macdonald et al. (1998). First, the satellite observations used in the present study cover only 4 months of the year, i.e. June to September, a period during which about $50 \%$ of the freshwater discharge occurs (McClelland et al., 2012). Assuming a constant SPM concentration in the river throughout the year, ex- trapolating our results to the winter period would lead to a total of $40( \pm 5) \times 10^{12} \mathrm{~g} \mathrm{yr}^{-1}$ for SPM, i.e., still different by a factor of 3 from the delivery estimated by Macdonald et al. (1998). As the organic SPM content is higher during the winter (5\% instead of $2 \%$ during the summer period (Yunker et al., 1993)), our summer estimates can be extrapolated to $1.3( \pm 0.1) \times 10^{12} \mathrm{gC}$ for the annual POC delivery into the delta, which still represents a $50 \%$ difference compared to estimates in Macdonald et al. (1998).

It is important to attempt to explain such differences. On the one hand, estimates based on field measurements by Macdonald et al. (1998) relied on data collected at least $100 \mathrm{~km}$ upstream of the delta zone (i.e., at the Arctic Red River station). The complex network of secondary streams branching off the river in the upper Mackenzie Delta may act as an efficient trapping for SPM, which would imply that an annual delivery of $120 \times 10^{12} \mathrm{~g}$ into the delta zone is an overestimation. This would correspond to mean depth-averaged SPM concentrations on the order of $500 \mathrm{~g} \mathrm{~m}^{-3}$ at the river mouth throughout the year, which is typically more than twice the values actually observed in the field during the MALINA oceanographic campaign and also significantly higher than SPM concentrations remotely sensed using MODIS satellite data (Doxaran et al., 2012). On the other hand, ocean color satellite observations are very scarce at best and therefore not exploitable in April and May, months usually associated with high river runoff and breakup of the stamukha and thus potentially associated with a maximum solid discharge into the delta. Moreover, the mean SPM concentrations obtained from satellite data vary slightly depending on the limits of the geographical zone in which the average is computed, as fine particles in suspension in the river freshwaters rapidly form flocs or aggregates as soon the water salinity becomes positive (Eisma et al., 1991). Therefore, suspended particles rapidly settle when they enter the delta zone, which leads to a lower concentration within the upper layer of the water column measured by the ocean color sensor. Finally, satellite observations measure only the SPM concentration in the first meter (if not less) below the airwater interface due to the rapid attenuation of the radiative signal. The satellite-derived SPM concentrations are therefore very well representative of the depth-averaged SPM concentration, as field measurements during the CASES 2004 (S. Bélanger, personal communication, 2015; CASES - Canadian Arctic Shelf Exchange Study) and MALINA 2009 experiments showed inherent optical properties constant with depth at the very shallow river mouth. However, the presence of a bottom nepheloid layer (BNL) cannot be detected by satellite data. The BNL is usually present at the downstream limit of the delta (Doxaran et al., 2012) and along the inner continental shelf (Ehn et al., 2015) and could play an important role in the SPM export from the river to the delta. In such a case, the SPM fluxes estimated using satellite data would provide an underestimation of the actual SPM loads delivered by the river to the delta. The true annual discharge of 
SPM by the Mackenzie River into the Beaufort Sea is probably between 40 and $120 \times 10^{12} \mathrm{~g}$. Only high-frequency measurements aboard in situ autonomous platforms installed at the mouth of the Mackenzie River and equipped with several turbidity sensors from the bottom (to sample the BNL) to the surface (to calibrate satellite data), together with detailed observations of current velocity profiles along and across the river mouth, could provide the information needed to draw conclusions on and accurately compute the SPM fluxes exported by the Mackenzie River.

\section{Conclusions and perspectives}

For the first time, to our knowledge, ocean color satellite data at a moderate spatial resolution $(1 \mathrm{~km})$ have been routinely processed over the recent 11-year-long period (2003-2013) to estimate and map the SPM concentrations at the mouth and along the plume of the Mackenzie River in the Canadian Arctic Ocean. The regional algorithm developed by Doxaran et al. (2012), initially applied to selected cloud-free MODIS scenes in 2009, 2010 and 2011, was here optimized to minimize the effects of sea ice, cloud and haze masks while also retrieving the seawater reflectance over the highly turbid waters of the Mackenzie Delta zone. This improved algorithm was applied to MODIS-Aqua satellite data to extract a maximum of information on SPM dynamics in the study area. As a result, SPM maps were produced each year for the period from the beginning of June to the end of September; the remaining months were discarded due to a lack of observations, a result of the combined effect of low solar light and of sea ice covering most of the study area. It was interesting to note that, probably due to effects of Arctic warming on the receding of sea-ice cover at high latitudes, a significant increase in the number of images with valid pixels was recorded in May and October after 2010. Lastly, sea-ice cover and SPM concentrations were superimposed to discard ocean color data possibly contaminated by the presence of sea ice and to study the combined dynamics of sea ice and SPM over the study area.

The monthly-averaged SPM and sea-ice maps produced were used to analyze the "seasonal" and interannual dynamics of SPM at the river mouth, in the delta zone and in the river plume. The highest SPM concentrations and largest extension of the plume were systematically observed in June, following the breakup of the stamukha and usually corresponding to the annual peak of the river freshwater discharge. As the river flow progressively declined from August to September, SPM concentrations gradually decreased in offshore waters but remained high in and around the delta zone where SPM did accumulate. This finding probably results from other processes involved in the transport of SPM, such as erosion due to permafrost thawing or extreme rain events. In addition to strong interannual variations, a trend was observed in both the delta zone and river plume, respec- tively corresponding to 50 and $35( \pm 5) \%$ increases in the SPM concentrations. Combined with the simultaneous augmentation of the Mackenzie River freshwater discharge over the same period $(+22 \%)$, the resulting SPM flux estimated at the river mouth significantly increased from 2003 to 2013 $(+46 \%)$, probably due to enhanced erosion processes along the drainage basin of the river. While on the same order of magnitude, the total masses of SPM (and terrestrial POC) exported by the Mackenzie River into the Beaufort Sea estimated using field measurements (Macdonald et al., 1998) and satellite data (our study) are significantly different, the latter being lower. The combined use of field and remotesensing techniques will be necessary in order to minimize the uncertainties associated with these estimations. These results are in agreement with the modeling study of Syvitski (2002), who predicted an increase of $20 \%$ in sediment load for every increase of $10 \%$ in Arctic river discharge. In our case, we found an increase of $46 \%$ in SPM concentration in the Mackenzie River delta for an increase of $22 \%$ in the freshwater river discharge. In a future study, the use of high spatial resolution ocean color satellite data (e.g., MODIS bands 1 and 2, respectively centered at 645 and 859 ; spatial resolution: $250 \mathrm{~m}$ ) should allow us to better understand the dynamics and transport of suspended particles at the river mouth (differentiating between the west and east river mouths) and in the delta zone, especially during the breaking of the stamukha.

The observed increase in the river discharge of SPM and turbidity (SPM concentrations), combined with changes in other key environmental factors in the coastal Arctic Ocean (Tremblay et al., 2011), will certainly have a rapid impact on the fate of the terrestrial organic carbon and on the marine ecosystems: ocean color satellite observations have already suggested an increase in the annual primary production in the Arctic Ocean (Arrigo et al., 2008).

Author contributions. D. Doxaran actively contributed to in situ bio-optical measurements in the study area and designed the regional SPM algorithm used in this study; he also contributed to its routine application to ocean color satellite data. E. Devred downloaded and processed the full time series of ocean color satellite observations and analyzed the trends observed in the variations in SPM concentrations and fluxes. M. Babin initiated the whole study and was the P.I. of the MALINA project (and oceanographic campaign). D. Doxaran prepared the manuscript with contributions from all coauthors.

Acknowledgements. This study was funded by ANR, the French Agence Nationale de la Recherche (MALINA project, P. I. M. Babin). We acknowledge the NASA GSFC for providing free access to MODIS satellite data and SeaDAS software and Environment Canada, specifically the Water Office www.wateroffice.ec.gc.ca, for providing the daily water discharge of the Mackenzie River main tributaries. 
Edited by: E. Boss

\section{References}

Arrigo, K. R., van Dijken, G., and Pabi, S.: Impact of a shrinking Arctic ice cover on marine primary production, Geophys. Res. Lett., 35, L19603, doi:10.1029/2008GL035028, 2008.

Arrigo, K. R., Perovich, D. K., Pickart, R. S., Brown, Z. W., van Dijken, G. L., Lowry, K. E., Mills, M. M., Palmer, M. A., Balch, W. M., Bahr, F., Bates, N. R., Benitez-Nelson, C., Bowler, B., Brownlee, E., Ehn, J. K., Frey, K. E., Garley, R., Laney, S. R., Lubelczyk, L., Mathis, J., Matsuoka, A., Mitchell, B. G., Moore, G. W. K., Ortega-Retuerta, E., Pal, S., Polashenski, C. M., Reynolds, R. A., Scheiber, B., Sosik, H. M., Stephens, M., and Swift, J. H.: Massive phytoplankton blooms under Arctic sea ice, Science, 336, p. 1408, doi:10.1126/science.1215065, 2012.

Bates, N. R. and Mathis, J. T.: The Arctic Ocean marine carbon cycle: evaluation of air-sea $\mathrm{CO}_{2}$ exchanges, ocean acidification impacts and potential feedbacks, Biogeosciences, 6, 2433-2459, doi:10.5194/bg-6-2433-2009, 2009.

Bélanger S., Ehn, J., and Babin, M.: Impact of sea ice on the retrieval of water-leaving reflectance, chlorophyll a concentration and inherent optical properties from satellite Ocean Color data, Remote Sens. Environ., 111, 51-68, 2007.

Carmack, E. C. and Macdonald, W. R.: Oceanography of the Canadian Shelf of the Beaufort Sea: A Setting for Marine Life, Arctic, 55, 29-45, 2002.

Chaillou, G., Anschutz, P., Dubrulle, C., and Lecroart, P.: Transient states in diagenesis following the deposition of a gravity layer: dynamics of $\mathrm{O}_{2}, \mathrm{Mn}, \mathrm{Fe}$, and $\mathrm{N}$-species in experimental units, Aquatic Geochem., 13, 157-172, 2007.

Doxaran, D., Froidefond, J. M., Lavender, S. J., and Castaing, P.: Spectral signature of highly turbid waters. Application with SPOT data to quantify suspended particulate matter concentrations, Remote Sens. Environ., 81, 149-161, 2002.

Doxaran, D., Froidefond, J. M., Castaing, P., and Babin, M.: Dynamics of the turbidity maximum zone in a macrotidal estuary (the Gironde, France): Observations from field and MODIS satellite data, Estuar. Coast. Shelf Sc., 81, 321-332, 2009.

Doxaran, D., Ehn, J., Bélanger, S., Matsuoka, A., Hooker, S., and Babin, M.: Optical characterisation of suspended particles in the Mackenzie River plume (Canadian Arctic Ocean) and implications for ocean colour remote sensing, Biogeosciences, 9, 32133229, doi:10.5194/bg-9-3213-2012, 2012.

Ehn, J. K., Reynolds, R. A., Stramski, D., Doxaran, D., and Babin, M.: Forced variability in suspended particulate matter patterns across the Canadian Beaufort Sea continental margin, Biogeosciences Discuss., submitted, 2015.

Eisma, D., Bernard, P., Cadeée, G. C., Ittekkot, V., Kalf, J., Lanne, R., Martin, J. M., Mook, W. G., Put, A., and Schuhmacher, T.: Suspended matter particle size in some West-European estuaries: Part II. A review on floc formation and break up, Netherlands J. Sea Res., 28, 215-220, 1991.

Emmerton, C. A., Lesack, L. F. W., and Vincent, W. F.: Nutrient and organic matter patterns across the Mackenzie River, estuary and shelf during the seasonal recession of sea-ice, J. Mar. Syst., 74, 741-755, 2008.
Forest, A., Babin, M., Stemmann, L., Picheral, M., Sampei, M., Fortier, L., Gratton, Y., Bélanger, S., Devred, E., Sahlin, J., Doxaran, D., Joux, F., Ortega-Retuerta, E., Martín, J., Jeffrey, W. H., Gasser, B., and Carlos Miquel, J.: Ecosystem function and particle flux dynamics across the Mackenzie Shelf (Beaufort Sea, Arctic Ocean): an integrative analysis of spatial variability and biophysical forcings, Biogeosciences, 10, 2833-2866, doi:10.5194/bg-10-2833-2013, 2013.

Franz, B. A., Bailey, S. W., Werdell, P. J., and McClain, C. R.: Sensor independent approach to the vicarious calibration of satellite ocean color radiometry, Appl. Opt., 46, 5068-5082, 2007.

Hedges, J. I., Keil, R. G., and Benner, R.: What happens to terrestrial organic matter in the ocean?, Org. Biogeochem., 27, 195212, 1997.

Keil, R. G., Mayer, L. M., Quay, P. D., Richey, J. E., and Hedges, J. I.: Loss of organic matter from riverine particles in deltas, Geochim. Cosmochim. Acta, 61, 1507-1511, 1997.

Li, W. K. W., McLaughlin, F. A., Lovejoy, C., and Carmack, E. C.: Smallest algae thrive as the Arctic Ocean freshens, Science, 326, p. 539, 2009.

Macdonald, R. W., Paton, D. W., and Carmack, E. C.: The freshwater budget and under-ice spreading of Mackenzie River water in the Canadian Beaufort Sea based on salinity and 18O/16O measurements in water and ice, J. Geophys. Res., 100, 895-919, 1995.

Macdonald, R. W., Solomon, S. M., Cranston, R. E., Welch, H. E., Yunker, M. B., and Gobeil, C.: A sediment and organic carbon budget for the Canadian Beaufort Shelf, Marine Geol., 144, 255273, 1998.

Macdonald, R. W., Harner, T., and Fyfe, J.: Recent climate change in the Arctic and its impact on contaminant pathways and interpretation of temporal trend data, Sci. Total Environ., 342, 5-86, 2005.

Markus, T. and Cavalieri, D. J.: An enhancement of the NASA Team sea ice algorithm, IEEE Trans. Geosci. Remote Sens., 38, 13871398, 2000.

McClelland, J. W., Holmes, R. M., Dunton, K. H., and Macdonald, R. W.: The Arctic Ocean estuary, Estuar. Coasts, 35, 353-368, 2012.

Meister, G., Franz, B. A., Kwiatkowska, E. J., and McClain, C. R.: Corrections to the calibration of MODIS Aqua ocean color bands derived from SeaWiFS data, IEEE Trans. Geosci. Remote Sens., 50, 310-319, 2012.

Nechad, B., Ruddick, K., and Park, Y.: Calibration and validation of a generic multisensor algorithm for mapping of total suspended matter in turbid waters, Remote Sens. Environ., 114, 854-866, 2010.

O’Brien, M. C., Macdonald, R. W., Melling, H., and Iseki, K.: Particle fluxes and geochemistry on the Canadian Beaufort shelf: implications for sediment transport and deposition, Cont. Shelf Res., 26, 41-81, 2006.

Overland, J., Bhatt, U., Key, J., Liu, Y., Walsh, J., and Wang, M.: Temperature and Clouds, Arctic Report Card: Update for 2011: Tracking recent environmental changes, available at: http:// www.arctic.noaa.gov/report11/temperature_clouds.html (last access: 2014), 2011.

Perovich, D., Gerland, S., Hendricks, S., Meier, W., Nicolaus, M., Richter-Menge, J., and Tschudi, M.: Sea ice. Arctic Report Card: Update for 2013: Tracking recent environmental changes, avail- 
able at: http://www.arctic.noaa.gov/reportcard/sea_ice.html (last access: 2014), 2013.

Price, D. T., Alfaro, R. I., Brown, K. J., Flannigan, M. D., Fleming, R. A., Hogg, E. H., Girardin, M. P., Lakusta, T., Johnston, M., McKenney, D. W., Pedlar, J. H., Stratton, T., Sturrock, R. N., Thompson, I. D., Trofymow, J. A., and Venier, L. A.: Anticipating the consequences of climate change for Canada's boreal forest ecosystems, Environ. Rev., 21, 322-365, doi:10.1139/er2013-0042, 2013.

Rawlins, M. A., Willmott, C. J., Shiklomanov, A., Linder, E., Frolking, S., Lammers, R. B., and Vörösmarty, C. J.: Evaluation of trends in derived snowfall and rainfall across Eurasia and linkages with discharge to the Arctic Ocean, Geophys. Res. Lett., 33, L0740,doi:10.1029/2005GL025231, 2006.

Rontani, J. F., Charriere, B., Sempéré, R., Doxaran, D., Vaultier, F., Vonk, J. E., and Volkman, J. K.: Degradation of sterols and terrestrial organic matter in waters of the Mackenzie Shelf, Canadian Arctic, Organic Geochem., 75, 61-73, 2014.

Serreze, M. C., Walsh, J. E., Chapin, F. S. I., Osterkamp, T., Dyurgerov, M., Romanovsky, V., Oechel, W. C., Morison, J., Zhang, T., and Barry, R. G.: Observational evidence of recent change in the northern high-latitude environment, Climatic Change, 46, 159-207, 2000.

Smith, C., Sheng, Y., MacDonald, G. M., and Hinzman, L. D.: Disappearing Arctic Lakes, Science, 308, 1429, doi:10.1126/science.1108142, 2005.

Shen, F., Salama, S., Zhou, Y., Jiufa, Li, Zhongbo(Bob), Su, and Dingbo, Kuang: Remote-sensing reflectance characteristics of highly turbid estuarine waters - a comparative experiment of the Yangtze River and the Yellow River, Int. J. Remote Sens., 31, 2639-2654, 2010.

Shiklomanov A. I. and Lammers, R. B.: River Discharge, Arctic Report Card: Update for 2011: Tracking recent environmental changes, available at: http://www.arctic.noaa.gov/report11/river_ discharge.html, last access: 2011.
Shiklomanov, A. I., Lammers, R. B., Rawlins, M. A., Smith, L. C., and Pavelsky, T. M.: Temporal and spatial variations in maximum river discharge from a new Russian data set, J. Geophys. Res., 112, G04S53, doi:10.1029/2006JG000352, 2007.

Syvitski, J. P. M.: Sediment discharge variability in Arctic Rivers: implications for a warmer future, Polar Res., 21, 323-330, 2002.

Tremblay, J. É., Bélanger, S., Barber, D. G., Asplin, M., Martin, Darnis, J. G., Fortier, L., Gratton, Y., Link, H., Archambault, P., Sallon, A., Michel,C., Williams, W. J., Philippe, B., and Gosselin, M.: Climate forcing multiplies biological productivity in the coastal Arctic Ocean, Geophys. Res. Lett., 38, L18604, doi:10.1029/2011GL048825, 2011.

Wang, M. and Shi, W.: The NIR-SWIR combined atmospheric correction approach for MODIS ocean color data processing, Opt. Express, 15, 15722-15733, 2007.

Wisser, D., Fekete, B. M., Vörösmarty, C. J., and Schumann, A. H.: Reconstructing 20th century global hydrography: a contribution to the Global Terrestrial Network- Hydrology (GTN-H), Hydrol. Earth Syst. Sci., 14, 1-24, doi:10.5194/hess-14-1-2010, 2010.

Yunker, M. B., Macdonald, R. W., Cretney, W. J., Fowler, B. R., and McLaughlin, F. A.: Alkane, terpene, and polycyclic aromatic hydrocarbon geochemistry of the Mackenzie River and shelf: riverine contributions to Beaufort Sea coastal sediments, Geochim. Cosmochim. Ac., 57, 3041-3061, 1993.

Zhang, Y., Li, J., Wang, X., Chen, W., Sladen, W., Dyke, L., Dredge, L., Poitevin, J., McLennan, D., Stewart, H., Kowalchuk, S., Wu, W., Kershaw, G. P., and Brook, R. K.: Modelling and mapping permafrost at high spatial resolution in Wapusk National Park, Hudson Bay Lowlands, Can. J. Earth Sci., 49, 925-937, doi:10.1139/e2012-031, 2012. 